\title{
Characterization of Calcium Phosphate Coating and Zinc Incorporation on the Porous Alumina Scaffolds
}

Hermes de Souza Costa ${ }^{\mathrm{a}}$, Marivalda Magalhães Pereira ${ }^{\mathrm{a}}$, Giovanna Ivo Andrade ${ }^{\mathrm{b}}$,

Edel Figueiredo Barbosa Stancioli, Herman Sander Mansur ${ }^{\text {a* }}$

${ }^{a}$ Laboratory of Biomaterials and Tissue Engineering, Department of Metallurgical and Materials Engineering, Federal University of Minas Gerais, R. Espírito Santo, 35, 30160-030 Belo Horizonte - MG, Brazil

${ }^{\mathrm{b}}$ Department of Microbiology, Institute of Biological Sciences, Federal University of Minas Gerais, P. O. Box 486, 31270-901 Belo Horizonte - MG, Brazil

Received: August 16, 2006; Revised: February 6, 2007

Bone ingrowth requires materials with the existence of open and interconnected pores with diameters larger than $150 \mu \mathrm{m}$ for proper circulation of nutrients. Such materials must possess enough mechanical strength to avoid failure whilst offering a bioactive surface for bone regeneration. We have developed porous ceramic alumina scaffold with compressive strength that achieves $3.3 \mathrm{MPa}$ by replication method by using the network structure of cellular polymer foam. However, the biocompatibility of ceramics based on $\mathrm{Al}_{2} \mathrm{O}_{3}$ requires further improvement so that it could have strong bonding to natural bone tissue. To address this problem of the interface between alumina and bone, we have developed a novel calcium phosphate with $\mathrm{Zn}^{2+}(\mathrm{CaP}-\mathrm{Zn})$ coating onto porous alumina ceramic scaffold by impregnating with calcium phosphate/poly(vinyl alcohol) slurry. The tri-dimensional alumina scaffold coated with CaP-Zn was extensively characterized by SEM, EDS and FTIR.

Keywords: scaffold, bioceramics, biomaterial, alumina, zinc

\section{Introduction}

In recent years, particular attention was paid to the synthesis of bioceramics with porous morphology to allow the ingrowth of bone tissue $^{1}$. The appropriate porosity and bioactivity allows the in-growth of bone tissue to achieve full integration with the living bones and the factors that affect the osteoconduction in the porous materials are the pore size, pore shape, pore connectivity, and bioactivity ${ }^{2}$. Ideally, the material should support compressive loading and tensile or torsion stress, however this can be difficult to conciliate with the fulfillment of the specifications for 3D structure ${ }^{3}$. Alumina bioceramics are being used in total joint replacement because of inertness, excellent biocompatibility and high wear resistence ${ }^{4}$. However alumina has a fundamental limitation as an implant material in that, like other "inert" biomaterials, a non-adherent fibrous membrane may develop at the interface. In certain circumstances interfacial failure can occur, leading to loosening of the implant ${ }^{5}$.

Many investigators have reported hydroxyapatite (Hap) coating on various implants, and it is know that hydroxyapatite coating stimulates bone formation ${ }^{6}$. Other aspect of particular importance is that has been increasing interest in the use of pharmacological agents to promote tissue regeneration around implanted biomaterials. Of the many trace elements, zinc is reported to be involved in bone metabolism ${ }^{7-10}$, showing that $\mathrm{Zn}^{2+}$ increases bone protein, calcium content, and alkaline phosphatase activity in rat calvaria ${ }^{11}$. Other role of zinc is protecting biological structures from damage by free radicals ${ }^{12}$.

In this study we presented a novel approach to obtain a potential bioactive surface in porous alumina scaffold. The basic concept involves coating a thin layer of calcium phosphate onto the surface of highly porous ceramic material based on alumina, followed by $\mathrm{Zn}^{2+}$ incorporation on the coating layer.

\section{Materials and Methods}

The calcium phosphate powder used in the experiment was synthesized following the procedure previously reported by our group ${ }^{13}$ with particle size below 400 mesh $(<38 \mu \mathrm{m})$ and $\mathrm{x}$ ray diffraction analysis (XRD) showing very low crystallinity degree with $78 \%$ of amorphous phase. The thermal treatment adopted in the synthesis of the calcium phosphate was limited to drying in the stove at temperature of $110^{\circ} \mathrm{C}$ for 24 hours.

All calcium phosphate suspensions used as coating layer were stabilized and dispersed by polyvinyl alcohol (PVA) with hydrolysis grade $98.0-98.8 \%$ and molecular weight between 13,000 and 23,000 (Celvol 107, Celanese Chemicals).

PVA aqueous solution with concentration $5.0 \mathrm{wt}$. (\%) (PVA/water ratio) was prepared by fully dissolving PVA granules in deionized water at $90 \pm 5{ }^{\circ} \mathrm{C}$ for 30 minutes. Then, $\mathrm{Ca}$-P powder was added to the just prepared PVA solution, at concentration of $5.0 \mathrm{wt}$. (\%) (CaP/PVA ratio), mixed for 15 minutes, obtaining a uniform and well-dispersed PVA/Ca-P suspension.

In the coating treatment porous alumina samples previously obtained by the foam replication were immersed in the calcium phosphate suspension, maintained for 30 minutes, then removed and dried at ambient temperature. The dried samples were immersed in ethanol (P.A., Sigma) solution containing 1 wt. (\%) $\mathrm{Zn}^{2+}$ (Sigma, P.A., $\left.\mathrm{Zn}\left(\mathrm{NO}_{3}\right)_{2}\right)$ for 30 minutes for zinc incorporation on the $\mathrm{CaP}$ coating.

$\mathrm{CaP}$ powder and porous scaffold obtained were characterized. Chemical compositions and pore structure were analyzed by Energy Dispersive $\mathrm{x}$ ray analysis (EDS) and scanning electron microscopy (SEM - JSM 360LV). Fourier Transform Infrared Spectroscopy Analysis (FTIR) was also used to analyze the coated samples. 
FTIR spectra were obtained within the range between 4000 and $400 \mathrm{~cm}^{-1}$ (Perkin-Elmer, Paragon 1000) using diffuse reflectance spectroscopy method. Samples were prepared by mixing with previously dried $\mathrm{KBr}$ powder $\left(110^{\circ} \mathrm{C}\right.$ for 4 hours). Samples were placed in a sampling cup and 32 scans were acquired at $2 \mathrm{~cm}^{-1}$ resolution with the subtraction of $\mathrm{KBr}$ background.

\section{Results and Discussion}

In Figure 1 are showed SEM micrographs of samples coated by immersion in the CaP/PVA suspension and with zinc incorporated onto the surface. In Figure 1a, it can be seen pore distribution and morphology with diameter ranging from 300 to $500 \mu \mathrm{m}$ with very small particles scattered and deposited on the surface of the alumina scaffold. EDS analysis (not showed) on the coated layer showed the presence of $\mathrm{Al}, \mathrm{Ca}$ and $\mathrm{P}$ peaks, indicating that the deposited coating is a calcium phosphate layer with a low concentration of $\mathrm{Zn}^{2+}$ incorporated. It is important to point out that, due to very low concentration of $\mathrm{Zn}^{2+}$ incorporated to the scaffold coated with CaP/PVA, the characteristic $\mathrm{Zn}(\mathrm{K} \alpha)$ line fell in the background range of the spectra. Moreover, it has been recently reported in the literature ${ }^{16,17}$ that using zinc associated with calcium phosphates has enhanced the bioactivity in bone tissue regeneration. However, $\mathrm{Zn}^{2+}$ at an elevated

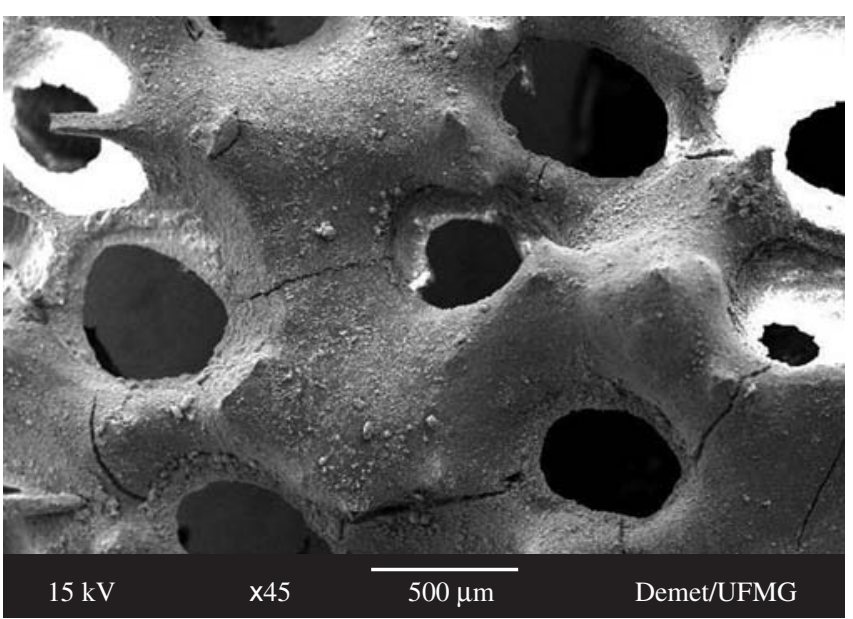

(a)

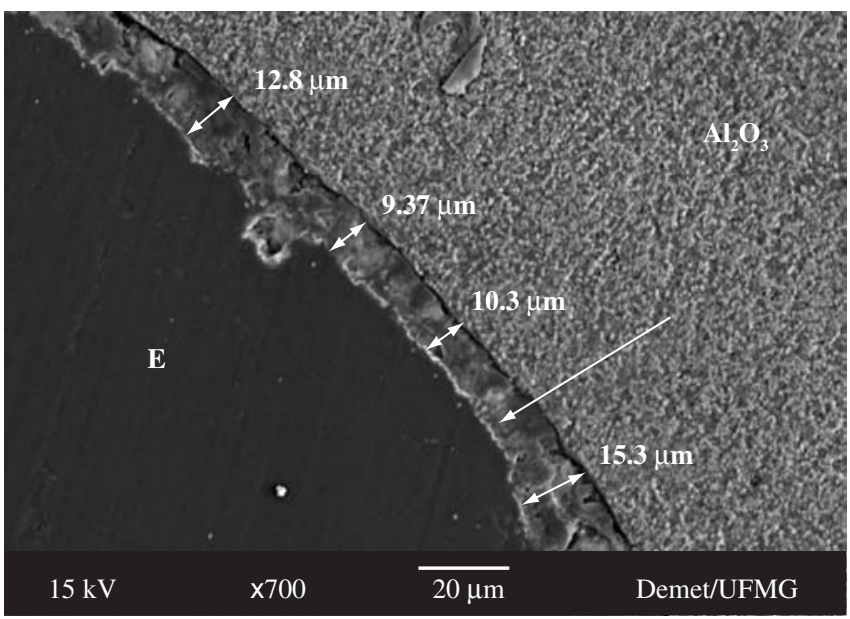

(b)

Figure 1. a) SEM micrographs of porous alumina scaffold coated in a CaP/PVA suspension followed by immersion in $\mathrm{Zn}^{2+}$ containing solution; and b) transversal section of embedded (E) sample showing the coating layer (arrow). level induces adverse reactions and must be released slowly from the implant. Hence, it has to be kept at the concentration of a doping element in the calcium phosphate based biomaterials.

A closer look on the pore region of embedded samples has allowed a much better visualization of the CaP/PVA coatings, as presented in Figure $1 b$. The thickness of the CP/PVA coatings varied between 20-30 $\mu \mathrm{m}$. It has clearly revealed a uniform coating layer, with average thickness of about $12.0 \mu \mathrm{m}$ in close contact with the alumina surface.

Chemical and physical properties on surface materials can be optimized to specific applications, maintaining the critical properties of bulk. By deposition of a coating with CaP/PVA suspension, we had obtained a layer with regular thickness, which resulted in a potential bioactive layer on macroporous alumina scaffold. In addition, the EDS analysis showed presence of zinc al low concentration level incorporated in the CaP/PVA coating of sample, which is an element that released at low concentration present pharmacological effect in bone metabolism ${ }^{16,17}$.

In Figure 2a is presented the FTIR spectrum of calcium phosphate powder used in the suspension deposited on the surface of alumina scaffold, that identified bands corresponding to the vibration modes of $\mathrm{PO}_{4}{ }^{3-}$ group $\left(565,599,960\right.$ and $\left.1041 \mathrm{~cm}^{-1}\right)$ and to $\mathrm{CO}_{3}{ }^{2-}$ group $(871$, 1414 and $1454 \mathrm{~cm}^{-1}$ ), characteristics of the apatites ${ }^{13}$.

FTIR spectrum of alumina samples immersed in CaP/PVA suspension followed by zinc incorporation (Figure $2 \mathrm{~b}$ ) showed the same bands as Figure $2 \mathrm{a}$ with the addition of vibration bands corresponding to the $\mathrm{C}-\mathrm{OH}$ at $1336 \mathrm{~cm}^{-1}$ of $\mathrm{PVA}^{14}$ and bands corresponding to the Al-O bonds ${ }^{15}$ in the region below $700 \mathrm{~cm}^{-1}$. Figure $2 \mathrm{c}$ presents the reference FTIR curve obtained from the alumina scaffold used on the production of porous tri-dimensional structure after thermal treatment at temperature of $1550{ }^{\circ} \mathrm{C}$.

Based on the FTIR results one can affirm that alumina was successfully coated by the proposed calcium phosphate suspension where all major vibration peaks associated with chemical groups were detected. Hence, FTIR results have endorsed the SEM and XRD findings that the 3D macroporous scaffold was coated by a CaP/PVA.

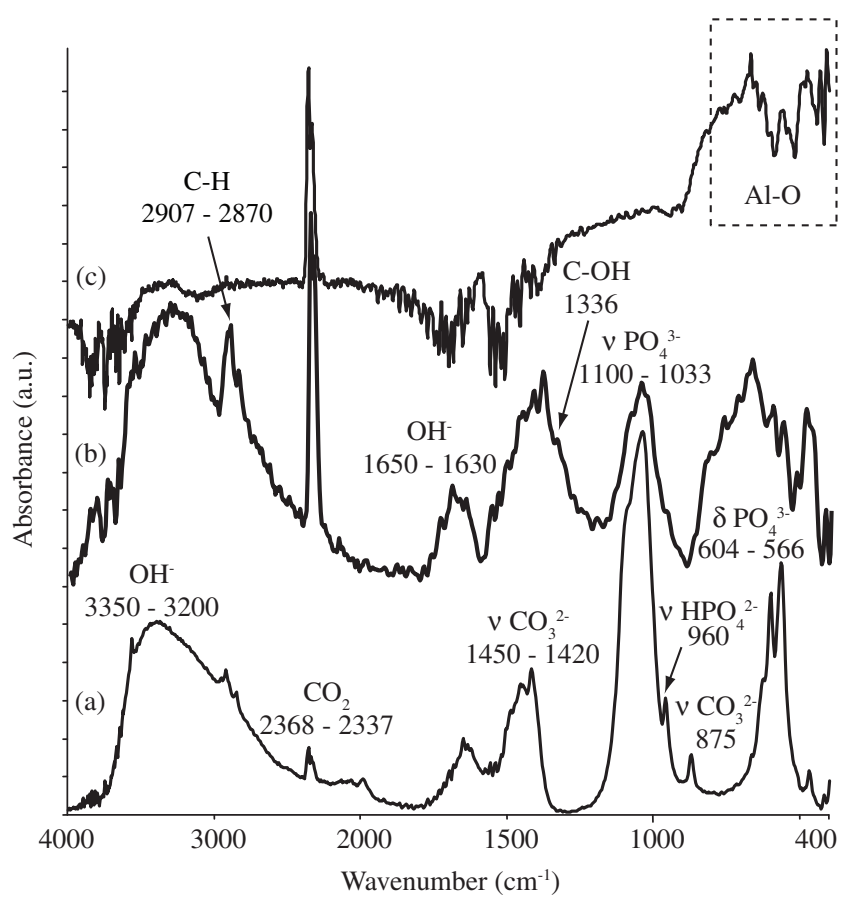

Figure 2. FTIR spectra of calcium phosphate and alumina powder (a and c, respectively) and of the alumina scaffolds coated with CaP/PVA. 


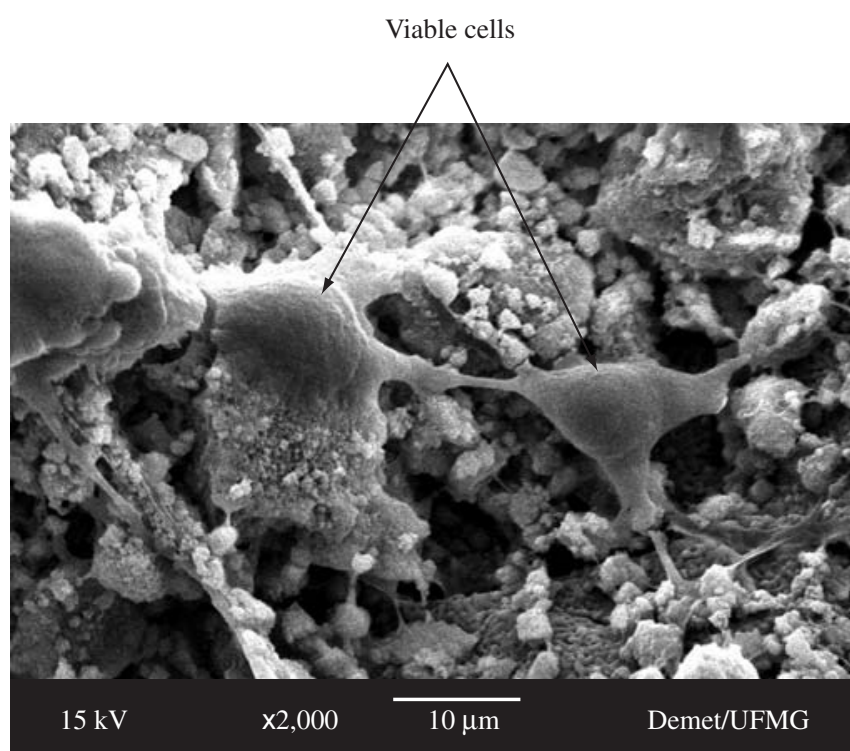

Figure 3. SEM photomicrograph of VERO cells spreading and attachment on alumina macroporous scaffold coated with CaP/PVA layer.

Biocompatibility was evaluated by VERO cell spreading and attachment assays. Viable cells were observed on the alumina porous scaffold coated with CaP/PVA as presented in Figure 3. SEM image showed in Figure 3 illustrates how viable cells spread onto biocompatible surfaces followed by the attachment. On the opposite, a cytotoxic material would have caused cell death and un-adhered to the biomaterial with a round-like morphology.

\section{Conclusions}

We have found strong evidence that a new method to obtain high strength material such as alumina with tri-dimensional porous structure and uniformly covered with a biocompatible coating of calcium phosphate doped with $\mathrm{Zn}^{2+}$ was developed. Such system has high potential to be used in bone tissue engineering.

\section{Acknowledgments}

The authors acknowledge CNPq/FAPEMIG/CAPES for financial support on this project. We are also grateful to Prof. Dr. Wander L. Vasconcelos for the FTIR spectroscopy facilities of Laboratório de Materiais Cerâmicos (LMC) and to Prof. Dr. Dagoberto B. Santos for the Microscopy Analysis Laboratory.

\section{References}

1. Tadic D, Beckmann F, Schwarz K, Epple M. A novel method to produce hydroxyapatite objects with interconnecting porosity that avoids sintering. Biomaterials. 2004; 25(16):3335-3340.
2. Jones JR, Hench LL. Regeneration of trabecular bone using porous ceramics. Current Opinion in Solid State and Materials Science. 2003; 7(4-5):301-307.

3. Olivier V, Faucheux N, Hardouin P. Biomaterial challenges and approaches to stem cell use in reconstructive surgery. Drug Discovery Today. 2004; 9(18):803-811.

4. Takaoka T, Okumura M, Ohgushi H, Inoue K, Takakura Y, Tamai S. Histological and biochemical evaluation of osteogenic response in porous hydroxyapatite coated alumina ceramics. Biomaterials. 1996; 17(15):1499-1505.

5. Cordingley R. Aluminia and Zirconia Bioceramics in Orthopaedic Applications. Journal of the Australasian Ceramic Society. 2003; 39(1):20-28.

6. Shi D, Jiang G. Synthesis of Hydroxyapatite films on porous $\mathrm{Al}_{2} \mathrm{O}_{3}$ substrate for hard tissue prosthesis. Materials Science and Engineering C. 1998; 6(1-2):175-182.

7. Ishikawa K, Miyamoto Y, Yuasa T, Ito A, Nagayama M, Suzuki K. Fabrication of $\mathrm{Zn}$ containing apatite cement and its initial evaluation using human osteoblastic cells. Biomaterials. 2002; 23(2):423-428.

8. Ito A, Kawamura H, Otsuka M, Ikeuchi M, Ohgushi H, Ishikawa K, Onuma K, Kanzaki N, Sogo Y, Ichinose N. Zinc-releasing calcium phosphate for stimulating bone formation. Materials Science and Engineering C. 2002; 22(1):21-25.

9. Sogo Y, Ito A, Kamo M, Sakurai T, Onuma K, Ichinose N, Otsuka M, Legeros RZ. Hydrolysis and cytocompatibility of zinc-containing $\alpha$-tricalcium phosphate powder. Materials Science and Engineering C. 2004; 24(6-8):709-715.

10. Ito A, Otsuka M, Kawamura H, Ikeuchi M, Ohgushi H, Sogo Y, Ichinose $\mathrm{N}$. Zinc-containing tricalcium phosphate and related materials for promoting bone formation. Current Applied Physics. 2005; 5(5):402-406.

11. Yamaguchi HO, Suketa Y. Zinc stimulation of bone protein synthesis in tissue culture. Activation of aminoacyl-tRNA synthetase. Biochemical Pharmacology. 1988; 37(21):4075-4080.

12. Tapiero H, Tew KD. The importance of glutathione in human disease. Biomedicine \& Pharmacotherapy. 2003; 57(3-4):399-411.

13. Santos MH, Oliveira M, Souza LPF, Mansur HS, Vasconcelos WL. Synthesis Control and Characterization of Hydroxyapatite Prepared by Wet Precipitation Process Materials Research. 2004; 7(4):625-630.

14. Bhat NV, Nate MM, Kurup MB, Bambole VA, Sabharwal S. Effect of $\gamma$-radiation on the structure and morphology of polyvinyl alcohol films. Nuclear Instruments and Methods in Physics Research B. 2005; 237(3-4):585-592.

15. Joe IH, Vasudevan AK, Aruldhas G, Damodaran AD, Warrier KGK. FTIR as a Tool to Study High-Temperature Phase Formation in Sol-Gel Aluminium Titanate. Journal of Solid State Chemistry. 1997; 131(1):181-184.

16. A Grandjean-Laquerriere, P Laquerriere, E Jallot, J Nedelec, M Guenounou, D Laurent-Maquin, T Phillips. Influence of the zinc concentration of sol-gel derived zinc substituted hydroxyapatite on cytokine production by human monocytes in vitro. Biomaterials. 2006; 27(17):3195-3200.

17. Jallot E, Nedelec JM, Grimault AS, Chassot E, Grandjean-Laquerriere A, Laquerriere P. STEM and EDXS characterization of physical-chemical reactions at the periphery of zinc-substituted hydroxyapatite during interactions with biological fluids. Colloid Surf B. 2005; 42(3-4):205-210. 
